\title{
Efficacy of Positive Airway Pressure on Serum Brain Natriuretic Peptide Levels in Patients with Heart Failure and Sleep- Disordered Breathing
}

\author{
Tomoyuki Kawada ${ }^{1}$
}

Received: 8 December 2015/Accepted: 2 January 2016/Published online: 12 January 2016

(C) Springer Science+Business Media New York 2016

To the Editor,

Zhang et al. conducted a systematic review by metaanalysis with six randomized controlled trials to know the efficacy of positive airway pressure (PAP) on the levels of serum brain natriuretic peptide (BNP), which is a biomarker of heart failure (HF), in patients with HF and sleepdisordered breathing (SDB) [1]. The authors selected random effect model, and concluded that a significant reduction of BNP was observed after PAP treatment in patients with HF and SDB. I have two queries on their study.

$\mathrm{Wu}$ et al. conducted a meta-analysis with six randomized controlled trials to know the effect of adaptive servo-ventilation (ASV) on serum BNP levels in patients with HF and SDB [2]. Although there was a decreasing trend in serum BNP level, pooled data from six studies showed no significant reduction. Three studies were having the same results with respect to subgroup of a meta-analysis by Zhang et al., and further meta-analysis is required in the future to confirm the above effect. In addition, Zhang et al. presented subgroup analysis of the efficacy of non-ASV procedure on serum BMP levels by using a study of Noda et al. [3]. As the authors did not check the superiority of ASV therapy against other therapy such as non-ASV procedure, further study is needed to assess the benefit of ASV.

Second, the authors used two sets of data by Randerath et al. with two different intervals of evaluation to know the efficacy of ASV on serum BNP levels in patients with HF and SDB [4]. Although I confirmed the standard mean difference of serum BNP levels after 12 months of treatment (not

Tomoyuki Kawada

kawada@nms.ac.jp

1 Department of Hygiene and Public Health, Nippon Medical School, 1-1-5 Sendagi, Bunkyo-Ku, Tokyo 113-8602, Japan
6 months in their Fig. 2), reconfirmation is needed for the standard mean difference of serum BNP levels after 3 months of treatment. In addition, please explain the difference of $\%$ weight between subgroups by Randerath et al. after 3 months and after 12 months in their Fig. 2. I suppose that the same \% weight would be presented.

Finally, I suspect that the efficacy of PAP on serum BNP levels in patients with HF and SDB differs by age. Mean age of subgroup data by Noda et al. [3] was 51.6 years and male $\%$ was not presented. In addition, Noda et al. handled patients with idiopathic dilated cardiomyopathy as a cause of HF. Taken together, the efficacy of non-ASV on serum brain BNP in patients with HF and SDB should be handled with caution.

Compliance with Ethical Standards

Conflict of Interest None.

Disclosure The author has indicated no financial support.

\section{References}

1. Zhang XB, Yuan YT, Du YP et al (2015) Efficacy of positive airway pressure on brain natriuretic peptide in patients with heart failure and sleep-disorder breathing: a meta-analysis of randomized controlled trials. Lung 193:255-260

2. Wu X, Fu C, Zhang S et al (2015) Adaptive servoventilation improves cardiac dysfunction and prognosis in heart failure patients with sleep-disordered breathing: a meta-analysis. Clin Respir J. doi:10.1111/crj.12390

3. Noda A, Izawa H, Asano H et al (2007) Beneficial effect of bilevel positive airway pressure on left ventricular function in ambulatory patients with idiopathic dilated cardiomyopathy and central sleep apnea-hypopnea: a preliminary study. Chest 131:1694-1701

4. Randerath WJ, Nothofer G, Priegnitz C et al (2012) Long-term auto-servoventilation or constant positive pressure in heart failure and coexisting central with obstructive sleep apnea. Chest 142:440-447 